The Fifth Scientific Conference of Obour Institutes

\title{
Quality of Educational Platforms
}

\author{
Dr. Ahmed Elsheekh ${ }^{1}$, Dr .Osama Mokhtar ${ }^{2}$ Dr. Hesham Gameel ${ }^{3}$ \\ ${ }^{1}$ Al-Obour Higher Institute for Management and Informatics \\ ${ }^{2}$ Al-Obour Higher Institute for Management and Informatics \\ ${ }^{3} \mathrm{Al}$-Obour Higher Institute for Management and Informatics
}

\begin{abstract}
What the world is witnessing today in terms of diseases and social distancing, in conjunction with the technological boom in communications and information technology, makes e-learning one of the most important priorities of governments at all levels. The real reality is the student explosion, as the number of secondary school students reached about ( 2 million) and vocational high school students ( 2 million), while the intermediate certificate also reached about (4 million) and the primary stage ( 8 million) in addition to students of institutes, higher institutes and universities. This requires us to increase the number of educational facilities at a rate of three times what is currently available during the next ten years, as the number of primary school students today has tripled than it is now, and this makes education a chronic economic crisis during the third decade of the twenty-first century. This article presents a new proposal for how modern technology can be used to solve education problems in Egypt, in addition to achieving the goals of sustainable development and education. It also provides a solution to the problems of distance education.
\end{abstract}

Keywords:- sustainable development, educational technology, education problems, education quality and digital transformation

\section{Introduction}

E-learning depends on the Internet, but there are always problems, which necessitates the state to establish an infrastructure. There is no doubt that performing exams at home and observing students using computers and mobile phones does not achieve strict and decisive control, in addition to laboratory experiments which needs strong interaction between students and the teacher This article presents new idea where, we can re-use the available technological tools to solve problems and achieve the following goals

1. Solve the problem of increasing student density in the classroom

2. Achieving interactive education between students and teachers

3. Doing final exams at home

4. Continuity of education in any discipline after obtaining a higher qualification in a different discipline. [1] , [2] , [3] ,[4]

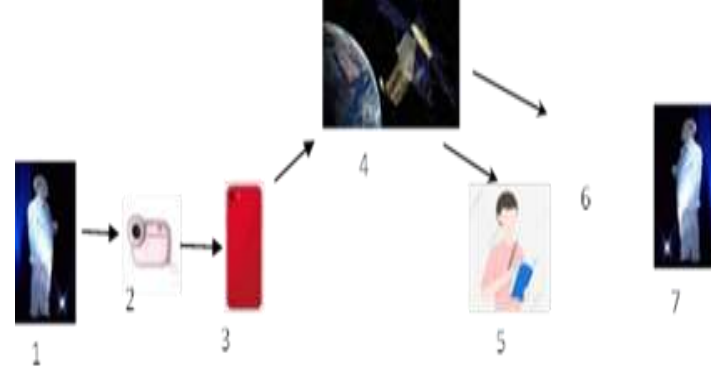

Figure (1) shows data path from teacher to students

We need continuous development to create an appropriate learning environment to achieve excellence of quality of educational outputs. Modern methods open new horizons for students to improve understanding, and research. In this article, we rely on direct communication via satellite instead of the leased line of internet, in addition to using the hologram as a technological means that has not been used before. 


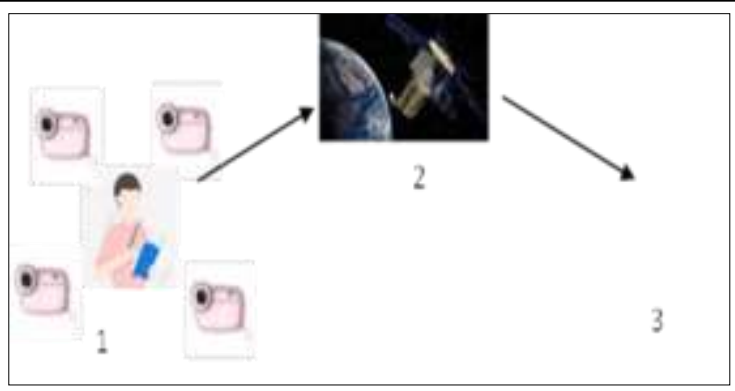

Figure (2) shows data path during final exam to achieve strong watch and control

\section{New Communications Platform}

Satellite and hologram are the available tools can solve all current problems and achieve our goals. The following figure $(1,2)$ shows the main elements proposed to be used in order to create interactive educational platforms.

Components of figure (1):

1- The teacher

2- Camera

3- Tablet

4- Tablets of many students

5- Hologram

6- Virtual reality of hologram

\section{Components of figure (2):}

1- Four cameras watching every single student.

2- Satellite receives data.

3- Data show displays 200 students on wall screen.

\section{History of Hologram Technology and Augmented Reality:} The two technologies went through many stages of development until they reached what

they are now and over the years a number of discoveries and research have been made by a number of scientists. Here is a brief illustration listing the history of both hologram technology and augmented reality technology over the years,

\section{Timeline of holography}

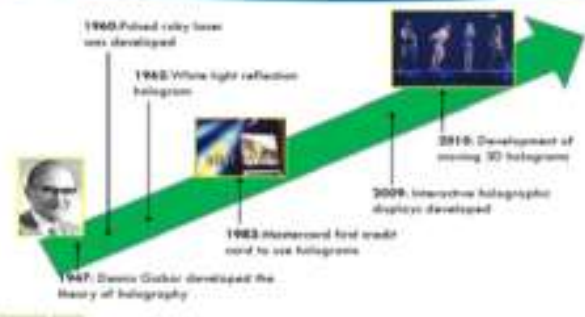

Figure (3) Hologram Technology history info-graphic showing the most important events that took place and the acceleration that both technologies went through until they reached what they are now:

\section{Hologram technology history:}

The Hologram was discovered in 1947 by accident when scientist Dennis Gabor was working on his research to develop electron microscopes. After its discovery, it was used in electron microscopes and was known as "electron holography ". Holographic imaging did not advance until the laser developed in1960. Figure 1 shows the timeline history of Hologram technology over the years (Holophile, Inc, 2010).

Augmented Reality technology history: Augmented reality was developed after Hologram technology

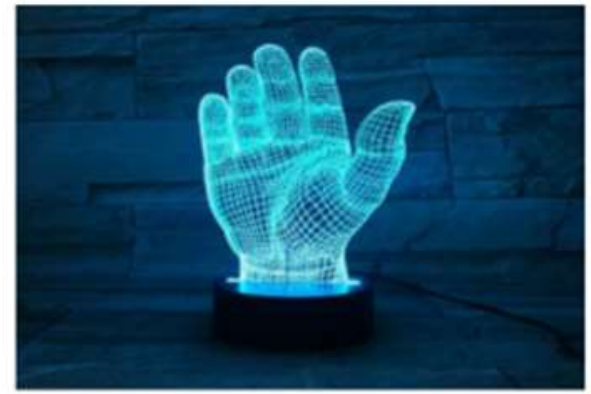

Figure (4). Floating 3D Hologram (Augmented Reality in Marketing: 8 Current Examples, n.d.)

Augmented Reality technology history:

Augmented reality was developed after Hologram technology by many years; the reason for this can be attributed to the fact that it is a technology that relied entirely on technology and programming, unlike Hologram technology, which was its primary basis dependent on devices, light, and physics, and then it evolved after that and became more dependent on technology. The following Figure (4) shows the timeline of Augmented reality technology and the most important events that It has undergone the development of this technology (Wong et al., 2014) (Bridget Poetker, 2019).

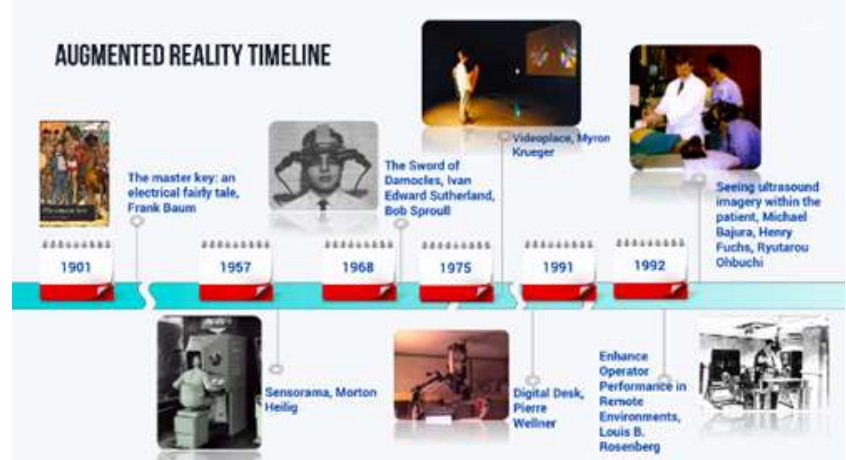

Figure (5) augmented reality Technology history infographic

Hologram Technology - Augmented Reality Images

Hologram technology and Augmented reality technology both give the users a 3D images that are 
floating in the reality and added to it, but this created image

differs in its properties and the method of creation, and to identify this difference; a classification of the image depending on its properties and creation method is listed for both Hologram technology and Augmented reality technology.

\section{Image properties}

\section{Hologram technology:}

The image is a 3D, really existed, and float in midair as shown in Figure (5) The observer can see the image directly without any additional devices like the 3D glasses or smartphone screen (Ibrahim et al., 2018).

\section{Augmented Reality technology:}

The displayed image is completely 3D virtual. As in Figure 6, the object added (augmented) to the real world and it would be visible to observer with the help of head-mounted displays, 3D glasses, or smartphone screen (Holography, 2020).

In both technologies, the user still sees the real world but receives additional information displayed but the effect of the presence is the biggest benefit of Hologram technology as there is no need to wear special glasses to see the 3D image (Ibrahim et al., 2018). On the other hand, the resolution of the object for $\mathrm{AR}$ exceeds the resolution of 3D hologram object owing to the effect of the mid-air in which the 3D hologram object is displayed.

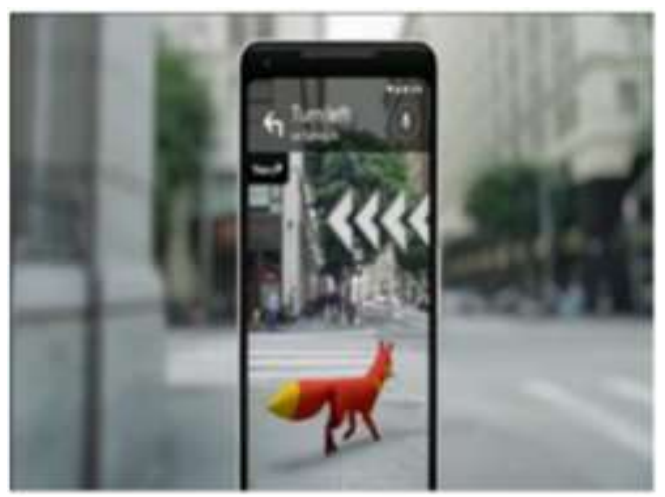

Figure (6). Augmented reality object (Spandana, 2019)

\section{E-Learning Coordination:}

Practical experiments inside homes: Physical innovations and discoveries made the world tread fast and moved the world from the era of darkness to the Renaissance. We note here the discovery of electricity that separated between the Middle Ages and the modern era, and the second discovery that will move the laboratories with all their devices to the home is the hologram. The use of the hologram will make the student see the devices and tools used (the anatomy of the corpse in medicine, the preparation of concrete in engineering, electrical experiments in the faculties of science and education, the dissection and mummification of animals in biology ..... etc.).

\section{Home essay exam:}

It is a very important, urgent and necessary goal, as the question will always be how to provide strict supervision while the student is taking the exam at home. In this research, the answer will be in the following context:

The student opens his device and uses the eye print as well as the fingerprint and facial features to identify the student's personality stored in the central computer of the educational institution. The student places the four cameras across the room in which he will be in his home during the exam and in a way that he can view all parts of the room. Thus, images will be sent to the student from each camera, not video, in order to facilitate the sending of the signal. Thus, strict supervision will be provided. As for writing the answers, the student can write whatever he wants, then take a photo of what he wrote and send the picture. The central computer collects the answers of each student in the database field for the student's record only, and it is corrected and the appropriate score is placed.

\section{Interactive education:}

The teacher will be able to view all his students attending via the data show device. A green mark will not appear indicating that the student is present in the lecture, as the student may have opened his device, but he is playing and not listening to the lecture. Therefore, the lecture using the satellite will turn into a real and effective presence without the current internet problems.

\section{The concept of the new educational institution:}

By using the previous proposal, the concept of the school will become slightly different from the previous one, as the educational facility will become a multi-use facility where classrooms and all buildings are used for primary school students who cannot be at home in a compulsive manner, but must be launched in schools in the morning, then the same institution is used for middle and high school students alternately throughout the week. The educational institution will be able to accommodate all numbers of students.

\section{Open and Continuing Education:}

Students can study whatever they want from different faculties without considering the student's total in high school, where he can join any college after completing his college that he joined as a group in high school through e-learning and payment of fees. After graduating, the individual can open channels for general culture, especially doctors. They can now enter the operating room with an infinite number using holograms and watch heart and brain surgeries and all micro-surgeries. As for the engineers and craftsmen, they will see the three-dimensional spare parts and how to repair them through the hologram, and the state can take advantage of that by collecting even a small fee for these services. 


\section{Work and Study:}

Students those work can carry the hologram and listen lecturer and show experiments during their work. Doctors can do surgery, all details will be shown by thousands students to learn and know fine details.

\section{Economic cost}

At first glance, it may seem that the cost of this project is very huge and it is not possible to provide financial resources for it, but, by placing some advertising and advertisements, as in satellite channels, the financial return will be very satisfactory. In addition to the participation of some countries in establishing this project for their students, several countries can participate in the satellite. One industrial area, and major institutions, especially telecommunications companies, can contribute to the financing of this project, and some channels can also be leased to some neighbouring countries to benefit from them. We note that the satellite dedicated to satellite channels achieves huge and incalculable profits from advertisements only.

\section{Conclusion}

Satellite and hologram are physicist innovation will change our world so very soon, will carry the world to the age of continuous existing. There are many aims and goals will be done and achieved. The most important aim is national security case due to student explosion addition to the next goals.

1) Practical experiments inside homes

2) The home essay exam

3) Interactive education

4) The concept of the new educational institution

5) Open and Continuing Education

6) Work and Study

\section{References}

\section{Website}

[1] https:/www.nasa.gov/audience/forstudents/58/features/nasa-knows/what-is-a-satellite-58.html

[2] https://www.swpc.noaa.gov/impacts/satellitecommunications

[3] https://www.youtube.com/watch?v=u5hQpRbHERg

[4] https://www.amazon.eg/-/en/ZYQZYQ-Illusion-

Wrecking-Children-

Decoration/dp/B082NVNWKG/ref=asc_df_B082NV NWKG/?tag=egoshpadde-

21\&linkCode $=$ df0\&hvadid $=545120121043 \&$ hvpos $=$ \&hvnetw $=$ g\&hvrand $=14498683207454573943 \&$ hvp one $=\&$ hvptwo $=\&$ hvqmt $=\&$ hvdev $=\mathrm{c} \& \mathrm{hvdv} \mathrm{cmdl}=\& \mathrm{~h}$ vlocint $=\&$ hvlocphy $=9073641 \&$ hvtargid $=$ pla$1440683276154 \& \mathrm{psc}=1$

[5] Holophile, INC., The History and Development of Holography, hologram, holograms, holography, holography exhibitions, holographic images, 3-D, 3dimensional images, Hologram, Holograms, Holography, Holography Exhibitions, Holographic Images, 3-D, 3-Dimensional Images. (2010). Holophile.Com.

https://www.holophile.com/history.htm.

[6] Wong, K., Jamali, S., \& Shiratuddin, M. F. (2014). A Review of Augmented Reality and MobileAugmented Reality Technology. The International Journal of Learning in Higher Education, 20, 37-54. https://doi.org/10.18848/14479494/CGP/v20i02/48690.

[7] Poetker, Bridget. (2019). A Brief History of Augmented Reality (+Future Trends \& Impact). G2.Com. https://learn.g2.com/history-of-augmentedreality.

[8] Algarawi, F. K., Alslamah, W. A., Alhabib, A. A., Alfehaid, A. S., \& Ibrahim, D. M. (2018). Applying Augmented Reality Technology for an E-Learning System. International Journal of Computer and Information Engineering, 12(3), 182-187.

[9] Holography. (2020, February 23). Retrieved from https://en.wikipedia.org/wiki/Holography.

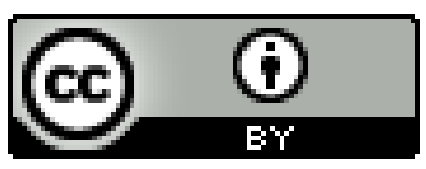

